\title{
Clarifying the Strategic Role of the HR Managers in the UAE Educational Institutions
}

\author{
Zahi Kamil Yaseen ${ }^{1}$ \\ ${ }^{1}$ College of Business Studies, Al Ghurair University, Dubai, United Arab Emirates \\ Correspondence: Zahi Kamil Yaseen, College of Business Studies, Al Ghurair University, Academic City, Dubai, \\ P.O.Box 34347, United Arab Emirates. E-mail: eibfs@yahoo.com
}

Received: November 18, 2012 Accepted: December 4, 2012 Online Published: March 13, 2013

doi:10.5539/jms.v3n2p110 URL: http://dx.doi.org/10.5539/jms.v3n2p110

\begin{abstract}
The education sector in the United Arab Emirates (UAE) is abounding with forceful challenges. The competition between the private educational institutions is not within the same country any more, but opens to global competition including countries in the Gulf Cooperation Council (GCC). This study aims to clarify the strategic role of human resource (HR) managers in the educational institutions in the UAE. Human resource management can play a strategic partner role in all organizations as well as in the educational institutions. Field data collection was accomplished by interview questionnaire survey and analyzed using SPPS. The findings revealed that HR's role in the UAE educational institutions is not as a strategic partner. Most of the HR activities in these institutions have mainly focused on the administrative aspects of human resource management. The findings offer rare insight into clarifying the strategic role of the HR managers in the educational institutions in UAE.
\end{abstract}

Keywords: human resource management, human capital, strategic HRM, UAE universities, UAE education

\section{Introduction}

The educational institutions in the United Arab Emirates (UAE) are replete with dynamic challenges. The competition is no longer limited to other educational institutions within the same country, but open to global competition including neighboring countries in the GCC, many of whom are capable to deliver prestige programs with international standards. The service of educational organizations is skilled through its human resources. Educational organizations' degree prospered in delivering high standards of educational programs will by the capability of the staff in achieving individual and group responsibilities. Human resource management has become known as an extremely important role in the function of administrators in the educational organizations, because of the acknowledgement, and the amount of societal forces.

In the field of management, many researchers highlight the competitive theme, introducing many strategies to gain competitive advantage in the market. Competition is apprehended as rivalry between groups, individuals, or nations that always arises when two or more parties struggle for something that not everybody can achieve (Eatwell, Milgate, Newman, 1987). Economic freedom is the key element of competition. When many suppliers emulate for the business of consumers, the cost of production well then be drawn toward prices, and goods and services that are considered to be in real demand will use scarce resources. Hence, competition brings about the utmost economic value, and makes use of minimum resources to respond to the increasing demand.

Normally when an industry has a strong intensive competition, it propensity gets more efficient and perfect. This is due to the fact that competition motivates the industry to produce only high quality standards and superior products for the end users. This is considered as an advantage to the general population as they will benefit from better quality products and services and may be for less.

Competition is a major factor in education. Students seek competition with their peers. Many modern education institutions encourage competitiveness among students through prizes, scholarships, and honor awards. Instructors and faculty members like students seek competition to get prestige jobs. The high ranked institutions encourage competitiveness among faculty members through attending educational conferences, seminars and workshops, and publications.

Conforming to Michael Porter's (1985) well known framework (the five principle competitive forces) that settle the capability of obtain above normal returns to the firms in the industry is to perceive having rivalry of the entry 
of new competitors (the intensity of competitive rivalry; the threat of substitute products or services; the bargaining power of customers (buyers); and the bargaining power of suppliers, Porter, 1985). Since elements of competitive achievements have become less important, the focus is on employees and their skills become crucial (Mello, 2006).

Most efficient management of human resources can be aligned with the company's competitive advantage and business capabilities (Noe, Hollenbeck, Gerhart, Wright, 2008).

This research paper investigates the role of the HR department in the educational institutions in the UAE. Arranged with a concise background, the study contains theories and hypothesis, as well as a methodology, and finally a conclusion that contains discussion and limitation of the study.

\subsection{Theory and Hypothesis}

HRM refers to the policies and procedures that affect employees' attitudes, actions, and performance (Noe, Hollenbeck, Gerhart, Wright, 2008). HRM activities involve analysis of jobs and design of work, in addition to planning, staffing, training, motivating, bargaining, improving working places, and employee relations (Werner, DeSimone, 2009). These practices have a direct influence on the overall organizations' performance and outcomes (Noe, Hollenbeck, Gerhart, Wright, 2008). Well trained and professional HR managers are able to recognize performers and prepare them for leadership positions. This process requires acknowledge of HR activities and jobs requirements of skills, tasks, responsibilities and decide whether a position suits the person or not (Cascio, 2006).

The best HR managers identify talents that are needed for a particular position and then find people who fit the role. This means looking beyond a person's knowledge and skills to size up whether a job really (fits) the person (Cascio, 2006). Human resource training and development concentrates on improving skills, knowledge, and change attitudes of individuals. The strategic view of HR training and development is helping to prepare employees for future work assignments, while improving their productivity on their current jobs (Werner, DeSimone, 2009).

Advanced technologies helps to streamline many HR functions through information technology programs to better control of HR practices (Bell, Won Lee, Yeung, 2006).

Professional HR managers develop performance improvement programs in response to competition in the marketplace and also for competitive advantage. They work hard to develop, design, and implement different programs in compensation, reward, and motivation to increase their organization's capacity for succession. HR managers should be sensitive to the prevailing attitudes and values in different cultures, therefore, (identifying the existence of cultural values should be an empirical question, not a priori assumption, Pratt and Rafaeli, 1997).

\subsection{Strategic Human Resource Management}

HR practices and effectiveness varies from one institution to another; the generic HR functions are administrative, business partner, and strategic partner (Noe, Hollenbeck, Gerhart, Wright, 2008). The basic HR function is the administrative function, which focuses on staffing, employee relation, and payroll services. Business partner is an advance function of HR that focuses on design, develop, and implement business plans. Strategic partner is the best and the most important from the three HR functions, it starts by contributing to business strategy based on the institution's capabilities, human skills, and developing HR strategic programs as (strategic differentiators, Noe, Hollenbeck, Gerhart, Wright, 2008).

Studies called for (Strategic Planning) to be implemented and to improve institutional actions and decisions for integrating HR practices to develop, design, and implement the strategic plan for competitive advantage (Wofford, 2002). Mello (2006) suggests (4Ps) of strategic human resource management starts with clear direction for the institution followed by identifying of the HR purpose and create positive climate to support the implementation of the HR policies, practices, and programs. David Ulrich (2008) at the University of Michigan developed an HR model called (Business Partner) clarifying the HR contribution to the institution strategy. First, he called for (information management) as the basic activity for the HR managers to set high standards criteria for recruitment, selection, employee retention, compensation, and training, then the focus must go to improve productivity of the whole organization. He claims that this requires that (HR managers should develop new ideas and adopt innovation to continuously increase the value of employee output while maintain or reducing the cost per unit). Ulrich emphasizes HR strategic contribution for the development of competitive advantage. 


\subsection{Background of Research}

In 1999, the Higher Ministry of Education and Scientific Research in the UAE established the Commission of Academic Accreditation (CAA) for the purpose of establishing international standards for private institutions and for accreditation needs. However, education in this part of the world and in UAE confront with serious challenges like (poor educational facilities, poor provisional training, low skill levels, serious skills mismatch, and deficient transfer of knowledge, Muysken, Nour, 2006). Moreover, all private educational institutions in this country provide education services for profit. This explain the rapid growth of this industry over the last few years, the aggressive recruitment of students, and the increased variety in the delivery methods used to provide education to students and the value of the education provided by such institutions.

According to a study conducted by a non-profit organization called "RAND Corporation" to examine the challenges that facing the (human capital in the $21^{\text {st }}$ century in the Arab World" revealed that "the existing education and training systems in UAE, Oman, and Qatar do not (effectively prepare students for the needs of the $21^{\text {st }}$ century global economy). The majority countries in the Gulf Region invested heavily in developing their educational systems to cope with the international standards, but this study revealed that (there is general acknowledgment that the quality of the primary and secondary education systems in these countries is not up to international standards).

In UAE higher education system, all educational institutions curriculum including public universities are primary built on the English language and the textbooks are imported from outside of the country. However, the Ministry of Higher Education and Scientific Research implemented what they called (Common Educational Proficiency Assessment, CEPA) for the purpose of determining which students should take a foundation year or two before admitting to the public universities (Farah, Ridge, 2009).

\section{Method}

This section includes the research sample, data collection, and questionnaire development.

\subsection{Sample}

The study was carried out through field self-administered questionnaire. The list of educational institutions drawn from 74 licensed universities listed in the directories of the Commission for Academic Accreditation of the Ministry of Higher Education and Scientific Research 2011. A random sampling method was used to select 50 samples. 35 respondents were actually responded.

\subsection{Data Collection}

Field data collection was accomplished by interview questionnaire survey between May and June 2011 in the UAE. The questionnaire's cover letter summarized the purpose of the study and handled in person to HR department in the selected list of institutions who arranged an appointment with HR directors or whoever is responsible for HR department. The low rate of response was due to (fear of disclosing internal information) or HR directors are not available. A total of 35 out of 74 completed the questionnaire.

\subsection{Questionnaire Development}

The questionnaire was established based on the literature review of this research paper. The development of this questionnaire concentrates on clarifying the role of HR managers in the UAE educational institutions. The participants were given the opportunity to express their views regarding the role they play in their institutions' strategic plan through quantitative and qualitative questions in the survey. We divided the survey into two sections. In the first section, we asked about demographic questions that addressed respondent's professional backgrounds and the role in their organization. In the second section, we asked for individual's perspectives on the HR profession.

\section{Results}

\subsection{Section I}

To determine the demographic characteristics of HR professionals in the UAE private educational institutions in which they work, we asked about their gender, age, level of education, years of experience, and job title along with the primary role in the institution.

\subsubsection{Gender}

The majority of our survey respondents were male with $89 \%$. Figure 1 illustrates the distribution of male and female responses. 


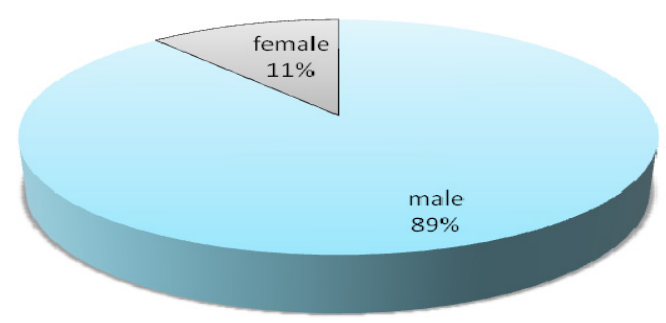

Figure 1. Gender

\subsubsection{Age}

In our survey, all age brackets, the majority of our respondents were over the age of 46 , approximately $28 \%$. While approximately $23 \%$ of respondents either less than 45 years and over 35 or between 56 and 65 . Figure 2 illustrates the distribution of age of the respondents.

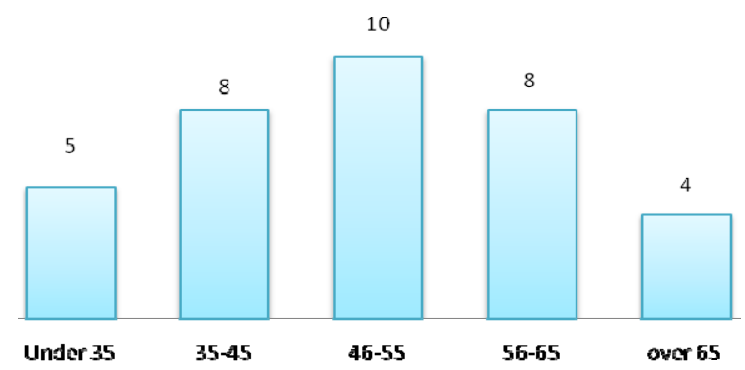

Figure 2. Age distribution

When we analysed the age of our participants according to gender, we found that the male respondents were, in general, older than female. For example, $80 \%$ of female are under the age of 35 .

\subsubsection{Education}

HR managers are well educated. Approximately $40 \%$ of respondents have earned bachelor's degree, while $23 \%$ of the respondents have earned a master degree. PHD holder degree exceeds $11 \%$ of the respondents and about $11 \%$ have earned a college diploma or certificate (Figure 3 ).

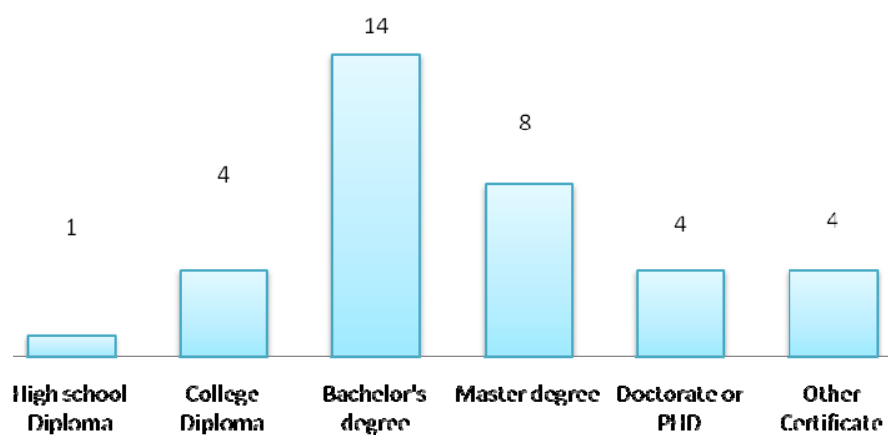

Figure 3. Level of education 


\subsubsection{Years of Experience}

The number of years of experience that an individual has in the HR field varies across respondents. As figure 4 illustrates, approximately $52 \%$ of our respondents have between one to 10 years of experience, with $17 \%$ of respondents having 11 to 15 years of experience, $14 \%$ from 21 to 25 years of experience and the remainder of survey sample split with either greater than 25 years or between 16 to 20 years of experience.

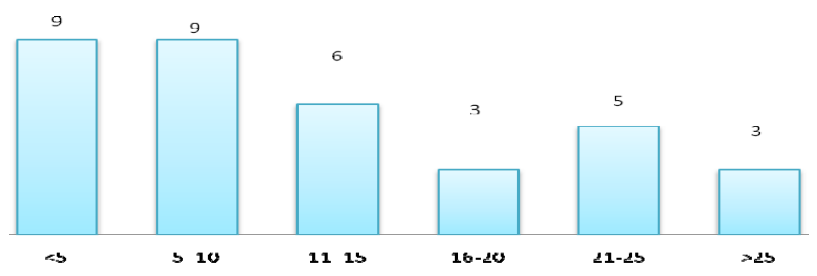

Figure 4. Number of years of experience in the HR profession

\subsubsection{Job Title}

Approximately $29 \%$ of respondents hold manager titles, $26 \%$ are directors, $17 \%$ are vice presidents, $14 \%$ hold titles that are professional in nature, $9 \%$ holds other titles, and $6 \%$ holds president title.

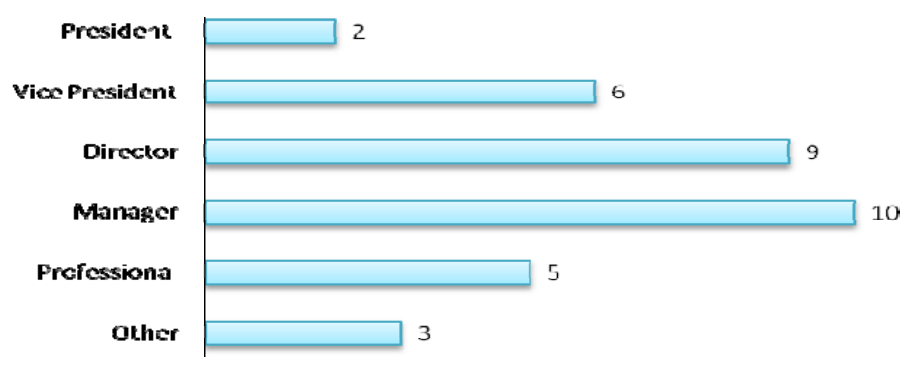

Figure 5. Job title

Our data show a statistically significant relationship between age, gender, and experience. That is, males in our research are, in general, older than females and have more experience in the HR profession (as measured in years of experience).

\subsubsection{Primary Role}

When asked what their primary role in their institution is, the HR professionals in our survey reported that they are predominantly HR administrators (71\%), are business partner (20\%), and are responsible for change in their institution or strategic partner (9\%). Figure 6 shows the primary roles held by our survey respondents.

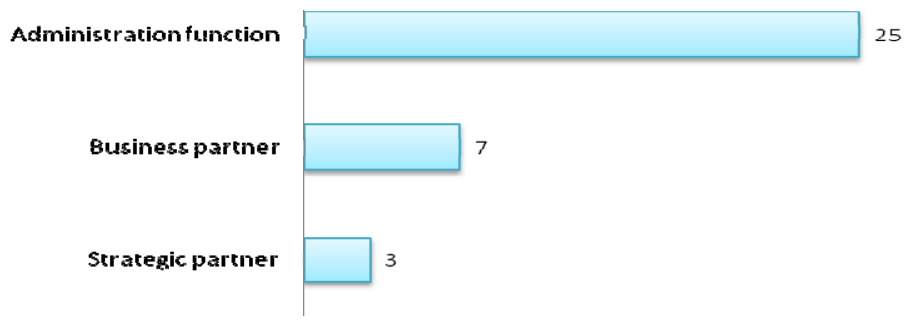

Figure 6. Primary role of HR professionals 


\subsection{Section II}

In this section, we asked the participants to provide their insights on the HR profession. Accordingly, we started this section with an outline of the HR activities in which participants are engaged, in addition to their perspectives on the key challenges and priorities for HR departments. Finally, the participants were asked about the skills and knowledge required by HR professionals.

\subsubsection{HR Activities}

In order to know what HR activities our participants involved, we listed the most important16 activities, and asked them to rank the extent of their involvement in each activity on a ten-point Likert scale ( $1=$ not involved at all ; $10=$ very involved). Respondents perceive that their involvement in all HR activities has increased. According to our survey results, the activities in which HR professionals are most involved include wage and salary administration, incentives and benefits, HR policies, security, staffing, employee relation and employee development (Figure 7).

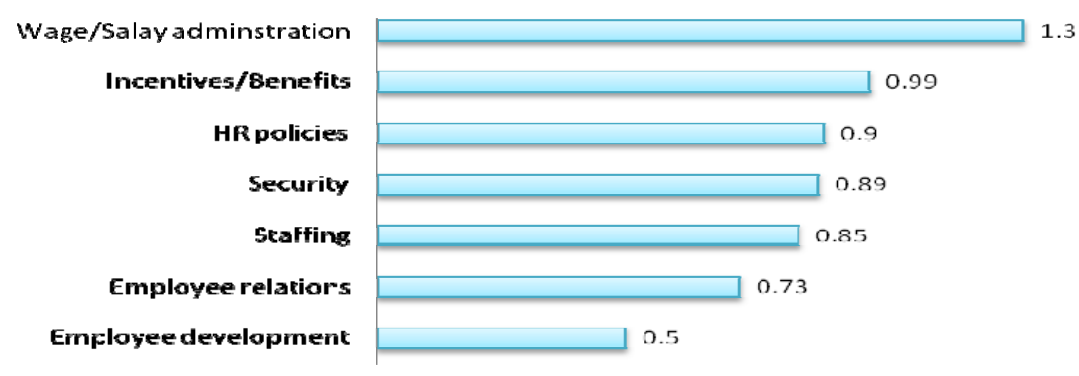

Figure 7. Top HR activities

\subsubsection{HR Challenges}

To determine the top seven HR challenges facing HR departments in the UAE private educational institutions, we asked our participants to rank a list of 20 items in order from the most significant to least significant. Once aggregated, we determined that reducing overall human capital costs is clearly the most significant challenge facing HR departments in the UAE educational private educational institutions. Building leadership capability is ranked as the second most significant challenge. Retaining key talent, driving cultural and behavioral change in the institution, increasing workforce productivity, workforce planning, and constrains on headcount were ranked three through seven respectively. Figure 8 shows the rank order of HR challenges, as perceived by survey respondents.

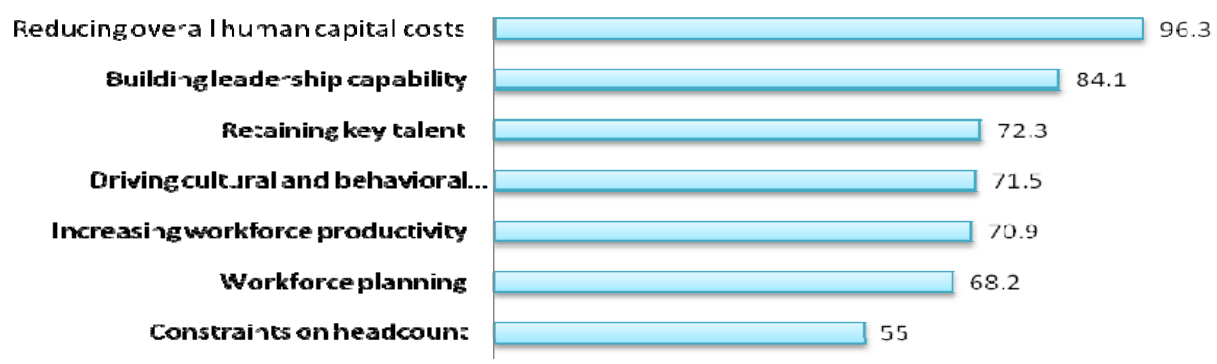

Figure 8. Top HR challenges

\subsubsection{HR Priorities}

In addition to HR challenges that institutions encounter, we also wanted to reveal the top five immediate priorities for HR departments. To do this, we asked two open-ended questions. We asked participants to list five immediate priorities. We then coded the responses and aggregated that data to determine the total number of occurrences for each priority, and put these priorities in rank order. Aggregate data reveal that the number one 
immediate priority for HR departments is building leadership capabilities. Driving cultural and behavioral change in the institutions ranked the second place. Tied for third place are retaining key talent and workforce planning, and increasing workforce productivity is in fifth. Figure 9 illustrates the immediate priorities for HR departments.

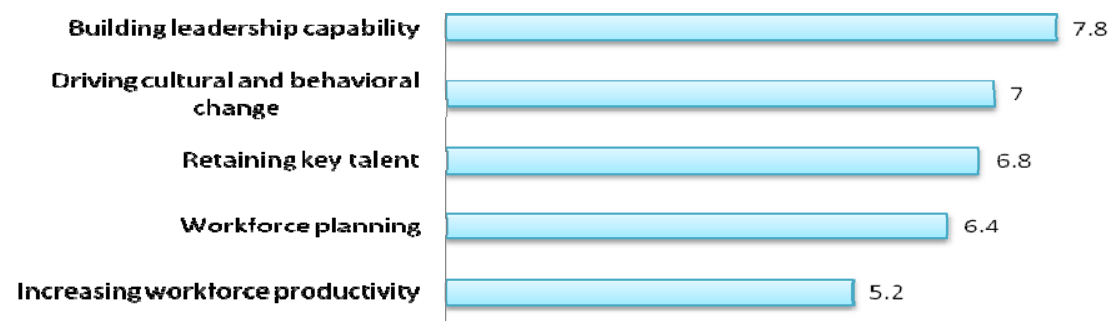

Figure 9. HR immediate priorities

\subsubsection{Critical Skills for HR Professionals}

Data revel that the top five skills that HR professionals think is communication, with $18.1 \%$ of the respondents including in their list. Analytical and strategic thinking is ranked second, cited by $16 \%$ of respondents, while conflict resolution is third, cited by $14.3 \%$ of respondents. Interpersonal skills, cited by $14 \%$ of respondents and technical skills, cited by $13 \%$ of respondents, are ranked fourth and fifth respectively (Figure 10).

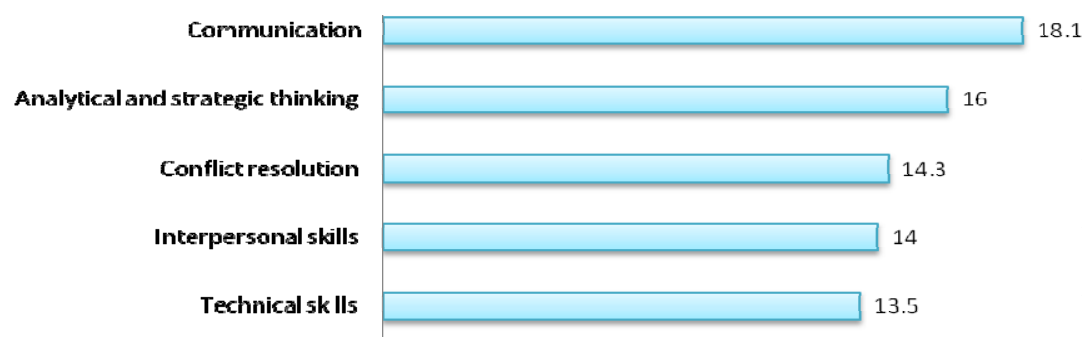

Figure 10. Top five critical skills for HR professionals

\subsubsection{Knowledge Required by HR Professionals}

Having identified the skills that are deemed critical for HR professionals, we asked the participants through open-ended question to list the top five critical pieces of knowledge that considered important for HR professionals. Data revel that the top five pieces of knowledge that HR professionals think is an understanding of business principles, with $20.3 \%$ of the respondents including in their list. Broad HR knowledge is ranked second, with $17.4 \%$ of respondents. An understanding of employment law and political power are tied for third and fourth, cited by $14.9 \%$ and $14.8 \%$ of respondents respectively. An understanding of the country political system is in the fifth place, with $13.5 \%$ of respondents (Figure 11).

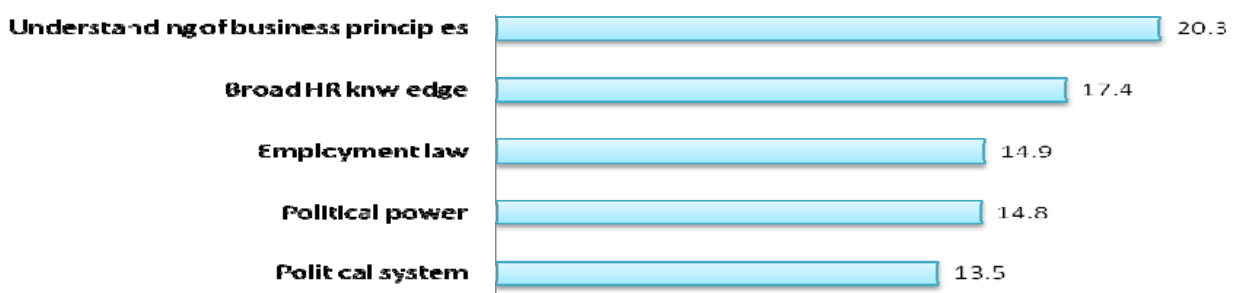

Figure 11. Top five pieces of knowledge critical for HR professionals 


\subsubsection{Training, Learning, and Development for HR Professionals}

Despite recognizing the skills and knowledge that are essential for HR professionals, less than $20 \%$ of our survey participants have a written career in place. While few have articulated their goals and objectives in writing, less than $30 \%$ of our survey participants do have budget for training, learning, and development (TLD). Figure 12 illustrates the distribution of training budgets across this group. Note that $51 \%$ of participants have annual TDL budget that are less than 10,000 AED or $\$ 2,700$, while $.03 \%$ of respondents have budgets that exceeds 100,000 AED or $\$ 27,200$.

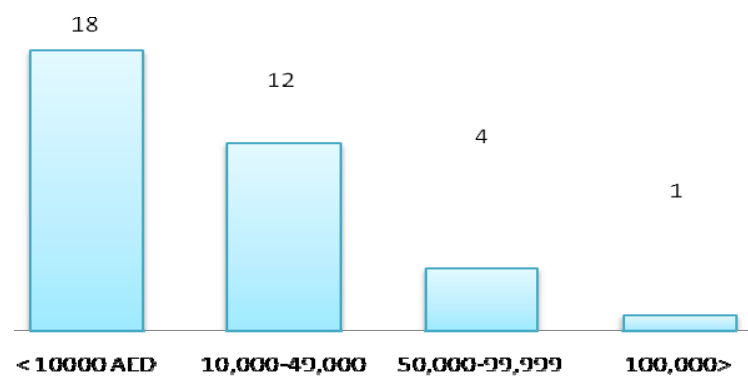

Figure 12. Distribution of TLD budgets

\section{Discussion}

The goal of this study was to examine the role of HR managers in the UAE private educational institutions. The findings suggest that HR departments in 35 educational institutions who responded to our survey confirmed the results in the finding section. Institutions rely on HR to strategically groom talent that will help them achieve high performance. Extending beyond a traditional focus on HR administration yields measurable results, improve profits, and enable an organization to grow for a long term. HR innovation is building on the cunning perspectives of the discipline to adjust with business strategy and excel the conventional approach of HR. Tasks such as applying benefits programs, salary administration, and development of employees will always carry central importance. However, by working in a strategic context including the HR role in coaching, connecting, and empowering a new generation, HR can make a direct impact on the bottom line and drive high performance.

Based on the results, the HR departments in the UAE educational institutions did not pass the first contribution of HR in organizations represented in the literature review. As proposed by Dave Ulrich (2008), it is providing information administration and simple arrangements by the processing of new hire documentation, payroll, and benefits induction HR managers need to have some degree of formal authority in order to complete the HR practices and functions and play a strategic role in the educational institutions.

Every institution strives to increase its profits and cut costs. However, HR has traditionally concentrated slightly all on the cost cutting basically because reducing people's cost is relatively easy. On the other hand, cutting people's costs can produce horrible consequences for example, failing to ascend worker productivity.

- Employing faculty members, staff, and administrators with lower competencies and talents is certainly cheaper than hiring individuals with extraordinary competencies, but it might negatively impact program creativity and growth.

- When high quality employees require more cash, they can be swapped basically with less expensive, but less effective employees that in the long run desire the need to employ a bigger amount of employees just to maintain the exact level of outcomes.

- Avoiding market compensation rates by other universities and underpaying in improvements greatly slows down the ability to employ and maintain high quality employees.

\subsection{Limitations of the Study}

This research study has been accomplished through other researches and questionnaires. However, it was not easy to bring in information from HR managers in additional organizations. This led to a research study that is fairly limited. Additional main research is necessary to simplify mechanisms underlying these findings, taking into consideration public educational institutions, culture, and authority styles. 


\section{Acknowledgements}

I would like to thank my colleagues for their support and all respondents for their cooperation.

\section{References}

Abu Dhabi Government. (2010). Commission for Academic Accreditation (CAA). Abu Dhabi, UAE: Government Website. Retrieved from http://www.abudhabi.ae/egovPoolPortal_WAR/appmanager/ADeGP/Citizen?_nfpb=true\&_pageLabel=p19 662\&lang=en

Bell, B. S., Lee, S. W., \& Young, S. K. (2006). The impact of HR on professional competence in HRM: Implications for the development of HR professionals (CAHRS Working Paper \#06-03). Ithaca, NY: Cornell University, School of Industrial and Labor Relations, Center for Advanced Human Resource Studies

Cascio, W. F. (2006). Managing Human Resources; productivity, quality of work life profits (7th ed.). New York: McGraw-Hill Irvin.

Eatwell, J., Milgate, M., \& Newman, P. (Eds.). (1987). Competition and Selection. The New Palgrave: A Dictionary of Economics, 1, 545-548.

Farah, S., \& Ridge, N. (2009). Challenges to Curriculum Development in the UAE. Dubai School Government, $\begin{array}{llll}\text { policy brief } & \text { No. } & \text { Retrieved } & \text { from }\end{array}$ http://www.dsg.ae/LinkClick.aspx?link=DSG+Policy+Brief+16+English.pdf\&tabid=308\&mid=826

Gonzalez, G., Lynn A. K., Louay, C., Hanine S., \& Charles A. G. (2008). Facing human capital challenges of the 21century: Education and labor marker initiatives in Lebanon, Oman, Qatar, and the United Arab Emirates. Santa Monica, CA: RAND Corporation. Retrieved from $\mathrm{http}: / /$ www.rand.org/pubs/monographs/2008/RAND_MG786.sum.pdf

Mello, J. A. (2006). Strategic Human Resource Management (2nd ed). Ohio: Thomson/South-Western Cengage Learning.

Michael, E. P. (1985). Competitive Advantage. New York, NY: Free Press.

Muysken, J., \& Nour, S. (2006). Deficiencies in education and poor prospects for economic growth in the Gulf countries: The case of the UAE. Journal of Development Studies. http://dx.doi.org/10.1080/00220380600774756

Noe, R., Hollenbeck, J., Gerhart, B., \& Wright, P. (2008). Human Resource Management: Gaining a Competitive Advantage (6th ed.). New York: McGraw-Hill, Irwin.

Pratt, M., \& Rafaeli, A. (1997). Organizational Dress as Symbol of Multilayered Social Identities. Academy of Management Journal. http://dx.doi.org/10.1080/00220380600774756

Ulrich. D. (2008). HR Competencies; Mastery at the Intersection of People and Business. The society for Human resource Management.

Werner, J. M., \& DeSimone, R. L. (2009). Human Resource Development (5th ed.). Ohio: Thomson/South-Western Cengage Learning.

Wofford, J. (2002). Competitive advantage: strategy and human resources. Journal of Applied Management and Entrepreneurship, 7(1), 135-47. 